\title{
Performance Optimisation of Coal-fired Boiler Control using Flownex® Simulation Environment and AI
}

\author{
L. van der Westhuizen ${ }^{a}$, I. A. Gorlach \\ Received 10 August 2020, in revised form 10 February 2021 and accepted 22 February 2021
}

\begin{abstract}
The inherent variability of renewable energy sources, pump storage plants and combined cycle gas turbines implies that coal-fired plants designed for continuous base load generation in South Africa must now be used for variable load. This has a negative effect on the overall efficiency and life expectancy of these plants. The challenge is, therefore, to balance the network demands with the power station operation, its thermal efficiency, availability and extended plant life expectancy. The focus of the current research is to monitor and optimise the efficiency of the boiler operation and control through modelling of the boiler subsystems during transient states. Flownex ${ }^{\circledR}$ Simulation Environment was used to model a generic boiler and a boiler control system in order to simulate thermo-fluid processes and critical boiler controllers. The developed model was evaluated based on plant data and optimised afterwards by means of PID controllers and Machine Learning algorithms. The process parameters obtained from the Machine Learning algorithms outperform that of the PID controllers for the selected controllers, such as: boiler load control and steam pressure control.
\end{abstract}

Additional keywords: Power generation, boiler control, boiler modelling.

\section{Introduction}

Steam generation is a critical parameter in coal-fired power plants. Thus, the control of critical parameters associated with a boiler system is imperative due to constant load changes, which is a common occurrence in the current electrical industry [1]. Frequently changing load disturbances occur as an increase in the number of renewable energy sources are being passed to the national grid. Therefore, coalfired power stations are not able to operate at a steady load and adjustments are constantly made to meet with the requirements of load conditions.

High-level control systems are used to achieve accurate control of boiler operations with the main purpose of maintaining a target set point value during boiler operation. Without the use of high-level control and interrelating systems in boiler control, the boiler system will not be able to perform steam generation as required. With the use of highlevel control systems, a large array of fine-tuning and optimisation methods are required in order to improve the

\begin{tabular}{clrr}
\hline a. & Mechatronics Department, Nelson & Mandela \\
& University, s214009246@mandela.ac.za. & \\
b. & Mechatronics $\quad$ Department, Nelson & Mandela
\end{tabular}

efficiency and responsiveness of boiler control, these optimisation methods are reported in [1-11].

Within the sub systems of a coal-fired power station, the task of a boiler is to produce the correct mass flow rate and temperature of steam which is passed to the steam turbines for the generation of electricity.

For a drum-type boiler, steam generation starts with the combustion of pulverised coal and air in the furnace of the boiler arrangement. The energy created from combustion is used to heat water in tubes within the furnace to generate saturated steam, the saturated steam then passes to a boiler drum in order to separate steam from water, figure 1. Dry steam is then superheated to the required temperature and passed to the turbine, which converts the steam energy into the mechanical energy to generate electricity.

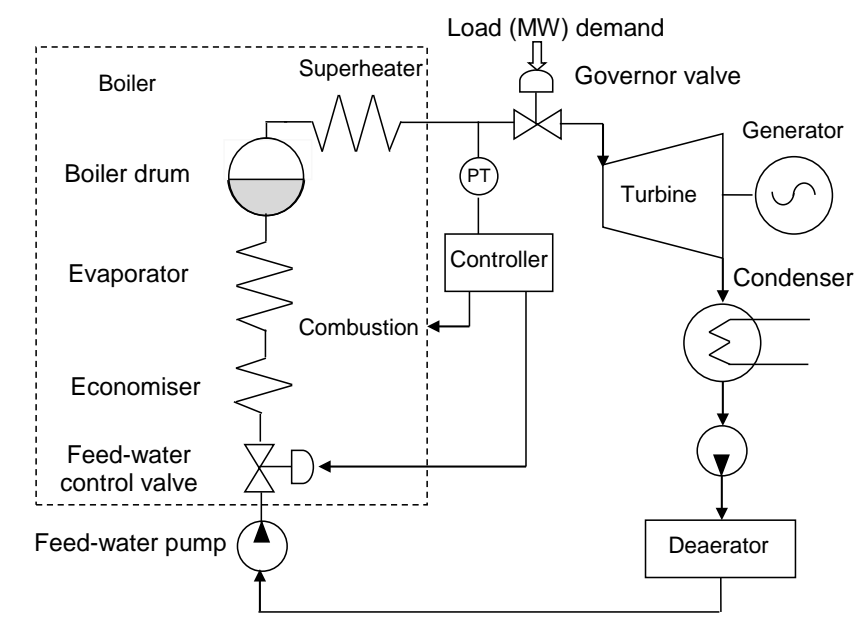

Figure 1 Schematic of a steam power plant (boilerfollowing mode)

The boiler can be controlled using various control modes depending on the national power demand as well as the capabilities of the power station. The control modes include boiler-following, turbine-following and coordinated-control modes. The various control regimes have differing responses to changes in megawatt (MW) load.

In the boiler-following mode, the MW load demand signal is referred directly to the control of the turbine governing valve, which is modulated to meet the MW load demand, figure 1 . This action allows for fast responses to changes in MW load as the stored steam energy in the boiler is utilised. As the steam flow changes due to movements of the governor valve, the boiler controller maintains a constant steam pressure by controlling the combustion process and the steam-water circuit accordingly. This control mode can rapidly respond to changes in load demand; however, the

$R \& D$ Journal of the South African Institution of Mechanical Engineering 2021, 37, 9-18

http://www.saimeche.org.za (open access) @ SAIMechE All rights reserved. 
control mode can only respond to small load changes as there is a limited allowable range of the pressure drop across the turbine governing valve [12].

Boiler-following control mode results in less stable pressure control as there is a lag between the turbine and boiler responses. This in turn creates undershoots or overshoots in the steam pressure set point. This mode is used in special cases and during manual control.

The preferred mode of operation is coordinated-control mode where the boiler and the turbine are controlled synchronously. However, this approach significantly complicates the control system.

Boiler-following mode as well as the boiler response will therefore be the focus of this study.

In order to produce an efficient and organised control structure within a plant, a control hierarchy is developed. The control hierarchy clearly distributes the controllers across several levels of control; the higher the level of control, the fewer manual interventions are required. In order to achieve such functionality, each hierarchical level is dedicated to a specific control measure and always depends on the lower collateral control level. If a lower control level in the hierarchy fails, the superior control level will not be affected and will allow the remaining hierarchy to control the power plant with full safety.

There are two forms of hierarchical control, namely binary and analogue. The objective of the binary control system is to provide set point values to subordinate control levels, which will ultimately reach the actuators to ensure the requirements are fulfilled [13]. The task of the analogue control system is to control the process variable of the defined set point, as well as control of drivers and actuators.

The efficiency of the boiler, which depends on the performance of the controllers and the executing systems, is determined by the critical process parameters, such as: MW load, steam pressure, steam temperature, furnace pressure, boiler drum level, residual oxygen $\left(\mathrm{O}_{2}\right)$ in the furnace, coal flow, air flow etc. These process parameters are constantly monitored in order to assess the health of and efficiency of the boiler and auxiliary systems. In this research, the focus is on two critical parameters and the corresponding controllers: the boiler load and the steam parameters.

\section{Thermo-fluid Model}

The developed thermo-fluid model using Flownex ${ }^{\circledR}$ consists of the boiler drum and turbine model. Together, both models are used to model the performance of various controllers related to the steam-water circuit which include the drum level, steam temperature, steam pressure and boiler load controllers.

\subsection{Steam-water circuit model}

The Flownex ${ }^{\circledR}$ steam-water circuit model is shown in figure 2. The feed-water, preheated to $210{ }^{\circ} \mathrm{C}$ in the economiser, enters the lower part of the drum where it mixes with the hot water. Due to natural circulation, the feed-water rises in the tubes of the evaporator while absorbing heat from the combustion of pulverised coal in the furnace. The water- steam mixture enters the drum where steam and water are separated. Steam is further heated in the two-stage superheater, where the steam temperature is controlled within the required range by means of water spraying in the attemperator before it is directed to the governor valve of the turbine.

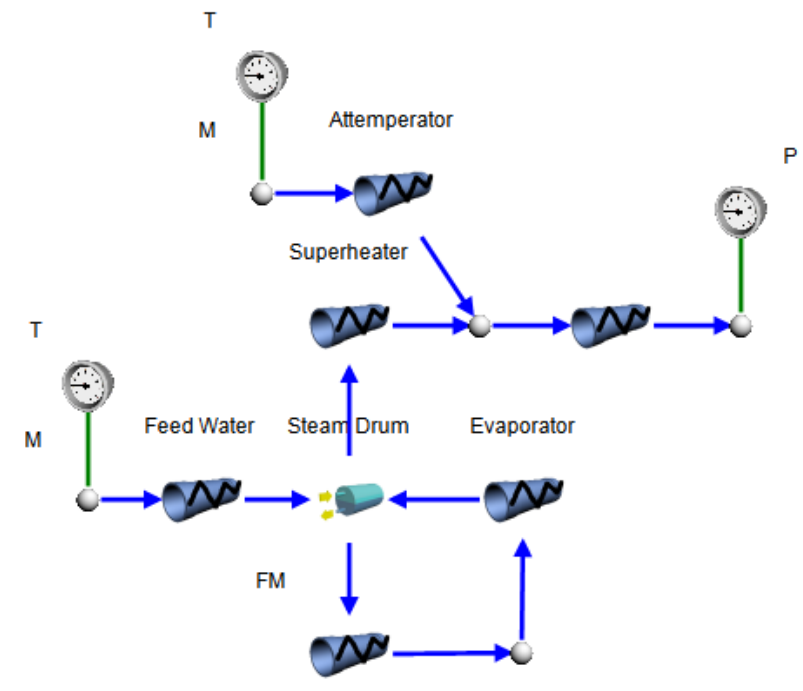

Figure 2 Flownex® steam-water circuit model

As the load changes, the steam flow is adjusted and as a result the water level in the boiler drum changes. The feedwater flow is then altered in order to maintain a steady water level. The boiler drum operating parameters used in modelling are shown in table 1.

Table 1 Boiler drum operating parameters

\begin{tabular}{lc}
\hline Parameter & Value \\
\hline Drum Pressure & $8500 \mathrm{kPa}$ \\
Drum Volume & $80 \mathrm{~m}^{3}$ \\
Drum Diameter & $2 \mathrm{~m}$ \\
Steam Mass Flow & $206 \mathrm{~kg} / \mathrm{s}$ \\
Evaporator Steam Temperature & $299^{\circ} \mathrm{C}$ \\
Feed-water Mass Flow & $200 \mathrm{~kg} / \mathrm{s}$ \\
Feed-water Temperature & $210^{\circ} \mathrm{C}$ \\
Down Comer Volume & $11 \mathrm{~m}^{3}$ \\
Riser Volume & $37 \mathrm{~m}^{3}$ \\
Drum Water Level & $0,48 \mathrm{~m}$ \\
Steam Quality & 0,21 \\
\hline
\end{tabular}

\subsection{Turbine model}

Figure 3 shows a turbine model, which consists of high pressure (HP) and low pressure (LP) turbines, connected on one shaft in the Flownex environment in order to study the direct effect each controller has on the overall plant efficiency. The shaft is specified to maintain a constant speed of $3000 \mathrm{rpm}$ which allows for varying load due to changes in steam mass flow. The design of the turbine network requires the turbine ellipse flow coefficient as well as the turbine isentropic efficiency.The main design parameters of the turbine model are specified based on actual plant data and shown in tables 2 and 3. 
The relationship between pressure deviation and steam mass flow within a turbine is expressed by means of the Ellipse law. The Ellipse law employs the definition of the flow coefficient denotes as $\Phi$, in cases of non-controlled expansion in multistage turbines. The equation is expressed as follows:

$\Phi=\frac{m}{\sqrt{\frac{p}{v}}}$

where

$$
\begin{aligned}
& m=\text { steam mass flow rate }(\mathrm{kg} / \mathrm{sec}) \\
& p=\text { steam pressure }(\mathrm{kPa}) \\
& V=\text { specific volume }\left(\mathrm{m}^{3} / \mathrm{kg}\right)
\end{aligned}
$$$$
\mathrm{T}
$$

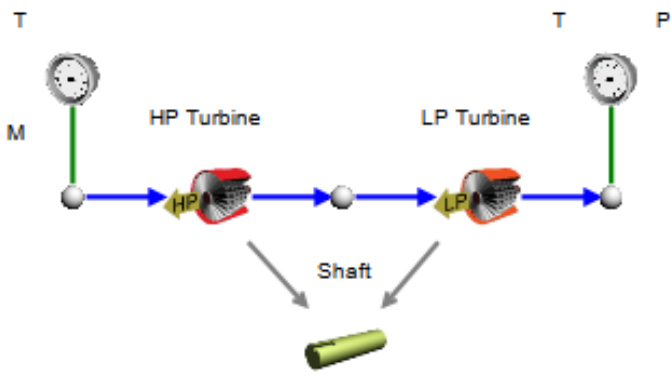

Figure 3 Flownex® turbine model

The inlet and outlet pressures of an adiabatic turbine are fixed as it undergoes a steady-flow process. Hence, the idealized process for a steam turbine is an isentropic process occurring between the exit and inlet steam pressure. The most significant output of the steam turbine is the work output. The definition of the isentropic efficiency of the steam turbine is calculated as the ratio of work output of the turbine during isentropic process and the actual work output.

The isentropic efficiency of turbine can then be written as

$\eta T \cong \frac{\left(h_{2 a}-h_{1}\right)}{\left(h_{2 s}-h_{1}\right)}$

where

$h_{1}=$ enthalpy at the inlet

$h_{2 a}=$ enthalpy of actual process at the exit

$h_{2 s}=$ enthalpy of isentropic process at the exit

The complete thermo-fluid model includes the steam drum and turbine network. The model has been developed to simulate the Camden Power Station. The relevant parameters including steam pressure, temperature, enthalpy and entropy are compared between the model and the actual plant.

Table 2 HP steam turbine design parameters

\begin{tabular}{lc}
\hline Parameter & Value \\
\hline Design Mass Flow & $240 \mathrm{~kg} / \mathrm{s}$ \\
Inlet Pressure & $10000 \mathrm{kPa}$ \\
Inlet Temperature & $510^{\circ} \mathrm{C}$ \\
Specific Volume & $0,085 \mathrm{~m}^{3} / \mathrm{kg}$ \\
Pressure Ratio & 15 \\
Ellipse Flow Coefficient & 0,95 \\
Isentropic Efficiency & 0,989 \\
Shaft Speed & $3000 \mathrm{rpm}$ \\
\hline
\end{tabular}

The complete thermo-fluid model was used to simulate the operation at $200 \mathrm{MW}$ load and the results were compared with the real plant data, figures 4-5. The simulation results show similar trends to the real power plant and, therefore, the thermo-fluid model can be used for the study of control strategies.

Table 3 LP steam turbine design parameters

\begin{tabular}{lc}
\hline Parameter & Value \\
\hline Design Mass Flow & $240 \mathrm{~kg} / \mathrm{s}$ \\
Inlet Pressure & $500 \mathrm{kPa}$ \\
Inlet Temperature & $510^{\circ} \mathrm{C}$ \\
Specific Volume & $0.66 \mathrm{~m}^{3} / \mathrm{kg}$ \\
Pressure Ratio & 5 \\
Ellipse Flow Coefficient & 2,75 \\
Isentropic Efficiency & 0,93 \\
Shaft Speed & $3000 \mathrm{rpm}$ \\
\hline
\end{tabular}

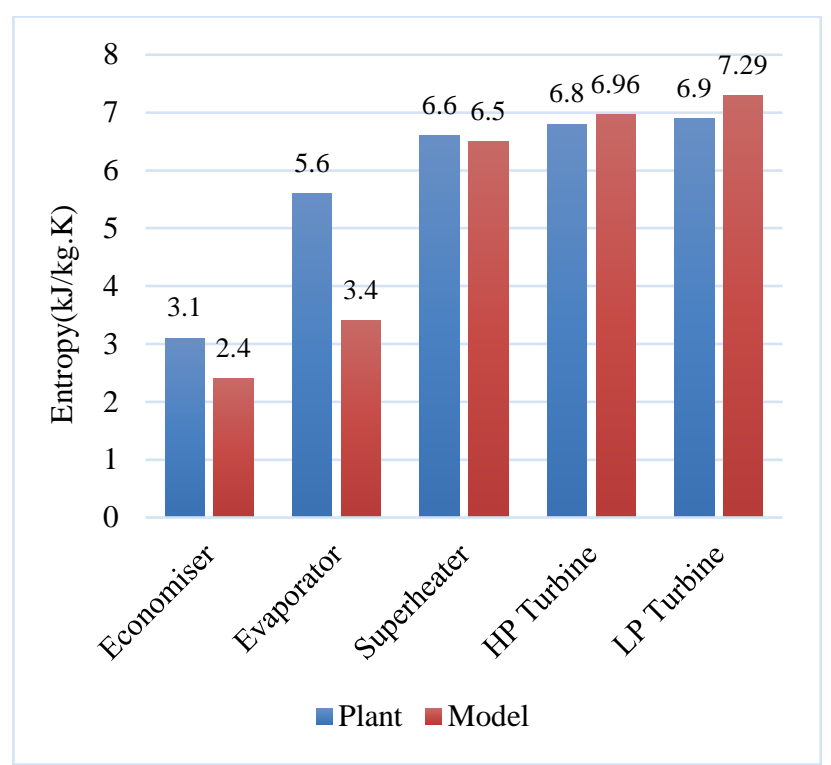

Figure 4 Comparison of entropy of actual plant and model

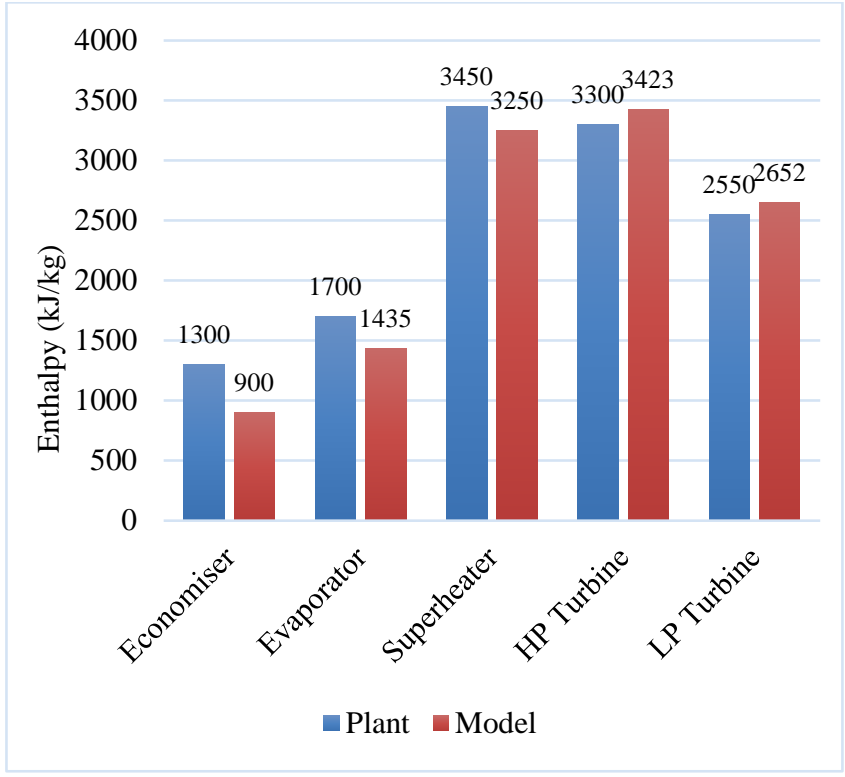

Figure 5 Comparison of enthalpy of actual plant and model

$R \& D$ Journal of the South African Institution of Mechanical Engineering 2021, 37, 9-18 


\section{Control Models}

The developed control models, based on the real plant controllers of a 200 MW power generation unit, were implemented and developed in Flownex ${ }^{\circledR}$ and interfaced with the thermo-fluid boiler-turbine model described above.

\subsection{MW Load Controller Model}

The determinant that controls all the boiler operations is called the 'master demand'. In a thermal power plant, steam is generated by burning fuel and the master demand sets the firing rate at a rate that is proportional with that of the steam production.
As described, an advanced type of control of the boilerturbine system is the coordinated control mode. In order to achieve a balanced control structure, the Unit Coordinator generates the MW demand of the boiler-turbine system using various computations, which is then distributed to both the Boiler Load and Turbine controllers as input load demands [12]. The developed MW load controller model combines the elements of Unit Coordinator and Load Controllers of a boiler, figure 6 . The MW set point is correlated with the values obtained by the capability computation and the efficiency units. The capability parameters depend on actual plant conditions and aggregates in service, such as: coal grinding mills, draught fans, feed-water pump and fabric filter plant.

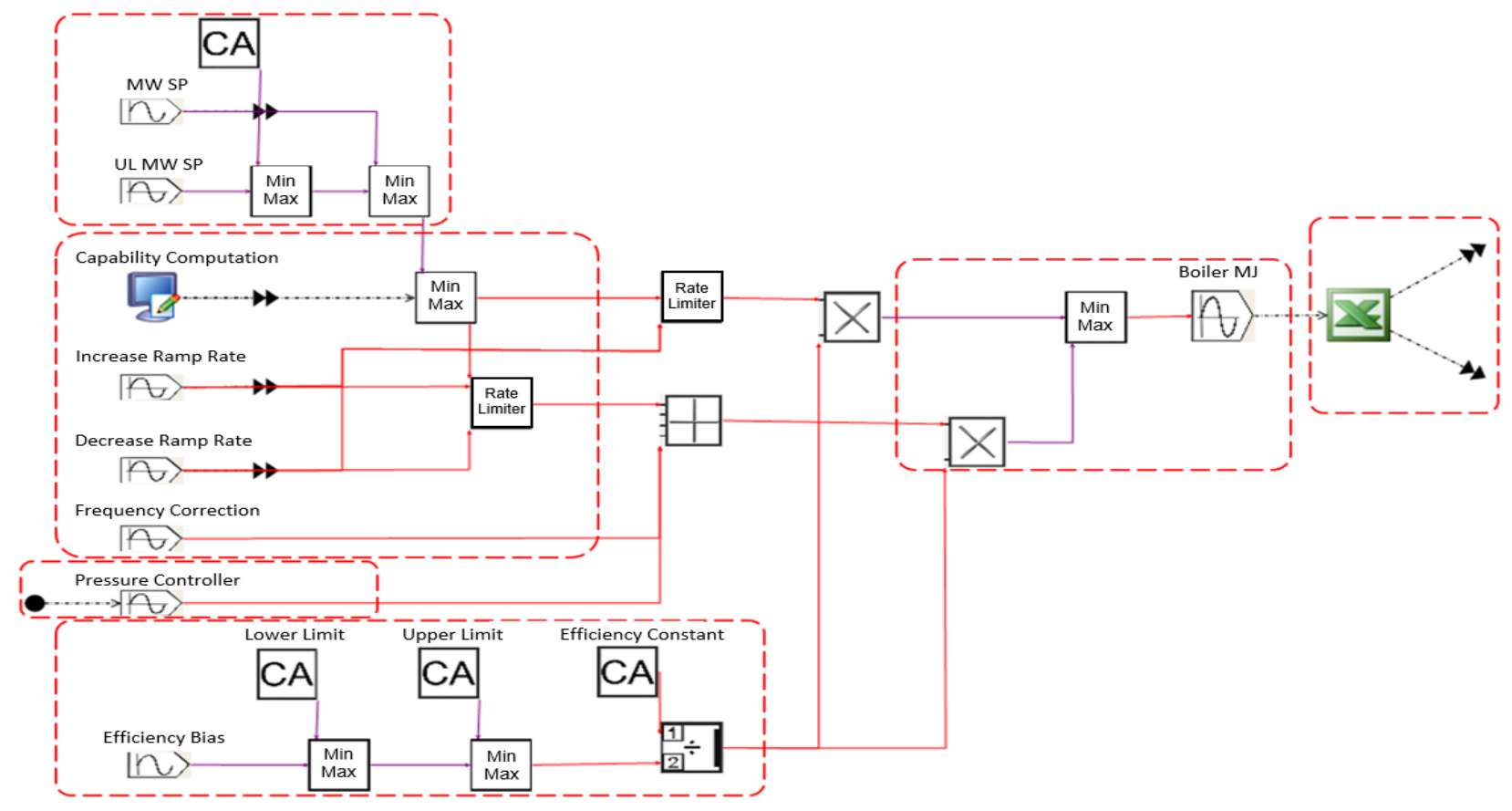

Figure 6 MW Load controller model

Frequency correction is responsible for keeping frequency within a $0.05 \mathrm{~Hz}$ dead band. If the frequency either decreases or increases outside of the dead band, the steam governing valve will automatically respond.

The efficiency unit is an operator changeable set point, which has limits of $0,9-1,1$. The operator selected value is then divided by an efficiency constant of 2,85 , thus producing an efficiency value [14]. Additionally, the unit efficiency constant is calculated by comparing the fuel demand with that of the generated MW. Once compared, the efficiency constant is then passed through MIN and MAX selectors to ensure that the efficiency constant is limited between the values 2,5 and 3,5. The unit efficiency is then multiplied by the unit load set point to determine the boiler fuel flow limitation in $\mathrm{MJ} / \mathrm{sec}$.

Efficiency constant $=\frac{\text { Boiler fuel demand }}{\text { Generator } M W}$

Using the calculated efficiency constant, the unit efficiency is calculated by comparing the operator changeable efficiency parameter towards that of the efficiency constant.

$$
\text { Unit efficiency }=\frac{\text { operator changable parameter }}{\text { Efficiency constant }}
$$

\subsection{Steam Pressure Controller Model}

The boiler steam pressure controller makes use of an energy balance between the drum pressure and the throttle pressure to develop a heat release computation, figure 7 . The energy balance forms a non-regenerative calculation which is selfcalibrating. This allows for lower fluctuations in boiler over firing or under firing. The output signal of the steam pressure controller is passed to the load controller which specifies a MJ boiler fuel requirement. Similar to the integration of throttle pressure error, the rate of change of boiler drum pressure is an indication of the boiler-turbine energy balance and can form a key role in the measurement and control of the boiler firing rate. System instability and cycling can be greatly reduced as well as the dependence of integral control by implementing the calculated heat release associated with the rate of change of drum pressure. 
The control system makes use of calculated heat release as fuel feedback and does not depend on coal feeder speed. The computation of heat release provides an instantaneous measure of the energy input to the boiler during fluctuations in load changes. Thus, the calculation of heat release is able to provide a total fuel computation.

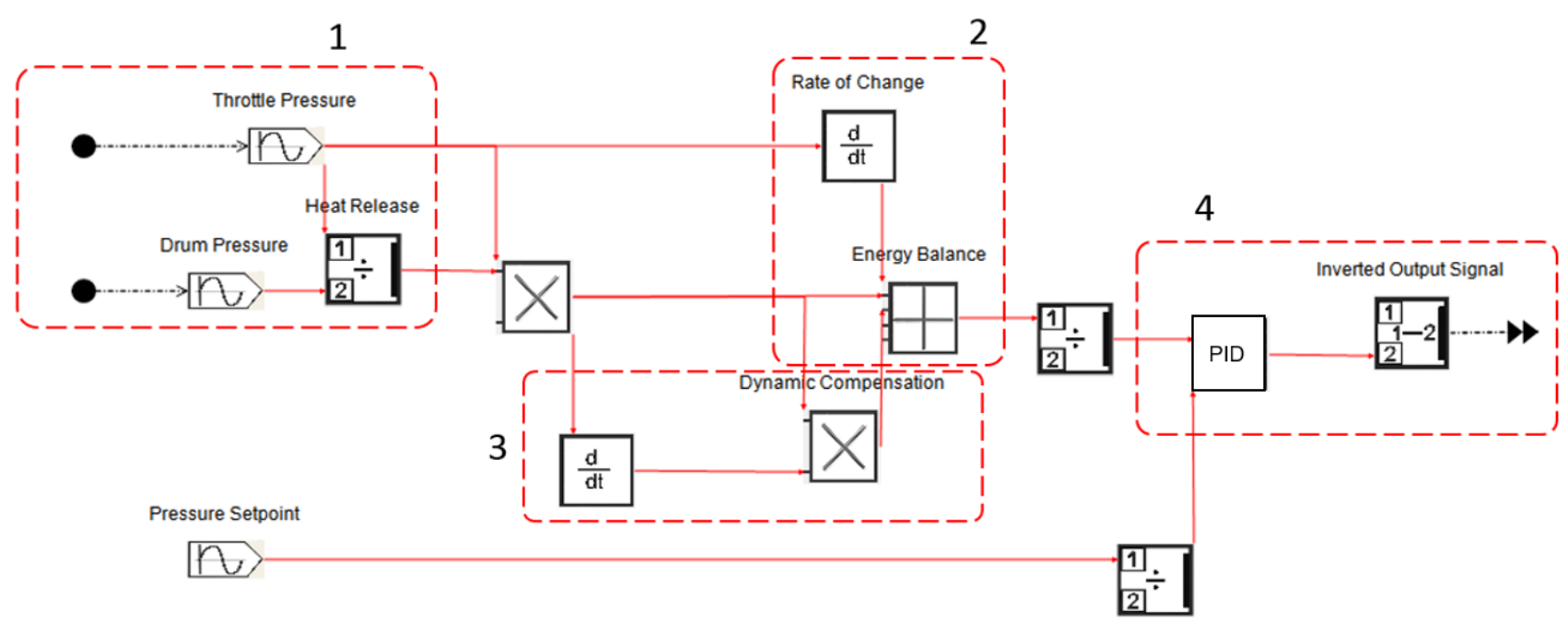

Figure 7 Steam Pressure controller model

The controller is able to achieve stable control of the throttle steam pressure (steam pressure prior to turbine governing valve) during successive changes in the set point value with the use of direct energy balance. Stable regulation of the process variable is achieved since both proportional and derivative control is used in the architecture.

The direct energy balance computation, which is calculated from a three-point control, serves as a selfcalibrating feedback signal based on energy demand which is able to alter the required boiler demand for increased/decreased stored energy required during load changes. The heat release computational model proves true for a number of changes in boiler firing rate and steam mass flow fluctuations during real time operation [15].

The cascade controller is able to provide a linear approximation of the governing valve operation with that of the load demand with the use of dynamic compensation and derivative action. Additionally, the controller allows for the implementation of frequency control for load changes.

The firing rate demand is a computation of the measure of the heat release from the boiler which is formed as a selfcalibrating turbine energy balance equation. The measurement of boiler demand is formed by determining the ratio of first stage turbine pressure to that of the measured throttle pressure, then comparing the calculated ratio to that of the throttle pressure set point. The fuel error is determined by comparing the difference in boiler demand based on turbine energy balance and that of the boiler heat release [15]. As mentioned, the heat release is calculated as the sum of the rate of change of drum pressure and first stage turbine pressure; temperature compensation is included in the computation of both terms respectfully.

The use of a heat release equation to maintain boiler energy with turbine demand is far more complex than single element steam pressure control. In this case, the boiler and turbine are not in a steam flow balance but rather an energy balance. The energy balance is nonlinear to steam flow and therefore must remain in balance for optimal plant operation.

\subsection{Machine Learning Controller}

The key advantage to using a neural network for control is the ability of the algorithm to achieve a desired value by means of processing the actual plant data. This deviates substantially from the use of numerical and statistical methods of control. In a control model, the output of the neural network is propagated through the plant and receives the plant's error as an input signal.

The Machine learning controller developed using Matlab ${ }^{\circledR}$ using custom script files to control the thermo-fluid model through means of Flownex ${ }^{\circledR}$ API's acts similarly to that of the PID controller. Where the artificial neural network accepts as inputs, the set point of the critical control parameter together with the error deviation (difference between set point and process value). The size of the neural network greatly depends on the complexity of the control object performed. Hence, as little hidden neurons are used as possible. This assists in reaching an optimal solution faster yet maintaining the complexity of the neural network.

The output of the neural network based on a given set of input data is calculated by means of a single feedforward pass through the network. The value produced by the output neuron serves as a control output which is passed to the actuators, figure 8 .

While a vast number of learning rules are available for training neural networks, the Gradient Descent learning rule is of the most widely used for training neural networks effectively. Because the neural network is used in a dynamic environment such as the PID controller, the neural network makes use of a stochastic learning rule, where weights are adjusted after each iteration. The next input pattern is selected 
from the thermo-fluid model after the output of the neural network has manipulated the process value. Hence, no prior training is implemented.

Provided an input pattern $z$ is given, the error bounded between the expected output and the actual output is given by the following equation:

$S S E=\varepsilon=\frac{1}{2} \sum_{k=1}^{K}\left(t_{k}-o_{k}\right)^{2}$

Illustrated in equation 5 , the sum of the squared errors is used such that $t_{k}$ and $o_{k}$ are the set point and process value of the control system respectively.

In order to optimise the neural network, a backpropagation algorithm is used to adjust the weights after each feed forward pass.

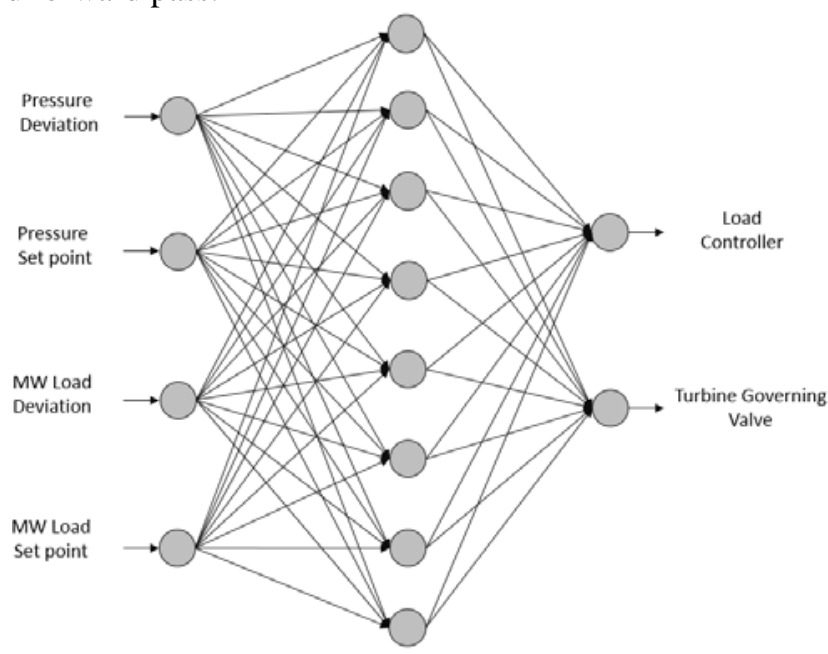

Figure 8 Machine Learning Controller

By using an artificial neural network that consists of a set of $I$ input neurons $\left\{z_{1}, z_{2}, \ldots, z_{I}\right\}$, a set of $J$ hidden layer neurons $\left\{y_{1}, y_{2}, \ldots, y_{J}\right\}$, each with a set of weights $\left\{v_{y, 1}, v_{y, 2}, \ldots, v_{y, i}, \ldots, v_{y, J}\right\}$ and a set of $K$ output layer neurons $\left\{o_{1}, o_{2}, \ldots, o_{K}\right\}$, each with a set of weights $\left\{w_{k, 1}, w_{k, 2}, \ldots, w_{k, i}, \ldots, w_{k, J}\right\}$, each output neuron, $O_{k}$, can be calculated as follows in equations $6-9$ :

$O_{k, p}=f_{o k}\left(\sum_{j=1}^{J+1} w_{k j} f_{y j}\left(\sum_{i=1}^{I+1} v_{j i} z_{i, p}\right)\right)$

Where $f_{o k}$ and $f_{y j}$ are the activation functions used for the output layer $O_{k}$ and the hidden layer $y_{j}$ respectively. $W_{k j}$ is the weight between output unit $O_{k}$ and hidden unit $y_{j} ; z_{i, p}$ is the value of input unit $Z_{i}$ of input pattern $Z_{p}$.

Such that $p$ is the number of input neurons. An activation function $f_{o k}$ and $f_{y j}$ are nodes which are added to the output layer or hidden layer of any neural network [16].

The Gradient Descent algorithm works by iteratively adapting each weight using the following formula:

$w_{k, j}(t)=w_{k, j}(t-1)-\eta \frac{\partial \varepsilon}{\partial w_{k, j}}$

The above formula holds true for updating hidden layer weights. It is thus necessary to differentiate the error with respect to the hidden and output layer weights.

It can be noted that the activation functions used for both output layer and hidden layer differ depending on the required output signal. Additionally, $w_{k j}$ and $v_{j i}$ represent the weights between both input layer and hidden layer as well as weights between hidden layer and output layer respectively. Through the training phase of a feedforward neural network, the weights $w_{k j}$ and $v_{j i}$ are updated using the following equations [16]:

$\frac{\partial \varepsilon}{\partial w_{k, j}}=\frac{\partial \varepsilon}{\partial o_{k}} \frac{\partial o_{k}}{\partial n e t_{o_{k}}} \frac{\partial n e t_{o_{k}}}{\partial w_{k, j}}$

$\frac{\partial \varepsilon}{\partial w_{k, j}}=-\left(t_{k}-o_{k}\right) o_{k}\left(1-o_{k}\right) y_{j}$

Similarly, the set of hidden neuron weights, $\left\{v_{y, 1}, v_{y, 2}, \ldots, v_{y, i}, \ldots, v_{y, J}\right\}$ are calculated as follows:

$\frac{\partial \varepsilon}{\partial v_{y, i}}=\sum_{k=1}^{K} \frac{\partial \varepsilon}{\partial o_{k}} \frac{\partial o_{k}}{\partial n e t_{o_{k}}} \frac{\partial n e t_{o_{k}}}{\partial f_{y j}} \frac{\partial f_{y j}}{\partial n e t_{y j}} \frac{\partial n e t_{y j}}{\partial v_{j, i}}$

$\frac{\partial \varepsilon}{\partial v_{y, i}}=\sum_{k=1}^{K}-\left(t_{k}-o_{k}\right) o_{k}\left(1-o_{k}\right) w_{k, j} y_{j}\left(1-y_{j}\right) z_{i}$

The weights are updated in accordance to the error between the measured output value and the desired output value [16]. Hence, the back propagation algorithm is used to improve the neural network's accuracy using the training data set (plant data).

The activation function assists in mapping the resulting value of a node to a desired range depending on the type of activation function used [16].

The Hyperbolic Tangent function is defined using equation 15:

$f(x)=\frac{e^{2 x}-1}{e^{2 x}+1}$

Unlike the Sigmoid activation function, the output of the hyperbolic tangent function is zero centred. The hyperbolic tangent function maps negative values as strongly negative while positive values are mapped as strongly positive, this avoids neurons from becoming saturated and in turn enforces effective training [16].

\section{Condition Monitoring}

In the process monitoring of the thermo-fluid model, it has been noticed that even during a stable load condition, the boiler control system variables and the associated executing mechanical sub-systems fluctuate while the set points remain constant.

The developed condition monitoring algorithm includes the following three parameters: the duty cycle, the total percentage movement of the process variable and mechanical actuators associated with it and the accuracy of the process variable [17].

The plant condition monitoring algorithms give a better understanding of how various control systems operate in different transient states. The primary focus on control systems is to develop a form of control that can reduce process variable fluctuations, thus increasing accuracy as well as reducing the duty cycle of mechanical actuators associated with that of a specific process variable. By reducing the process variable fluctuations as well as the duty cycle of mechanical actuators, the efficiency of the plant can be drastically increased. 
The algorithms used to measure the duty cycle of mechanical actuators, accuracy and total percentage movement of process variables are given in the equations below.

The equation below illustrates the calculation of the duty cycle of an actuator which is denoted as the fraction for which an actuator is active during a specific cycle time.

Duty Cycle $(\%)=\frac{\text { Active time }}{\text { Total cycle time }} \times 100$

The total percentage movement of the process variable is calculated using the equation below where $X_{\mathrm{i}}$ denotes a reading of the process variable over a number of iterations denoted as $n$.

Total Movement $(\%)=\sum_{i=1}^{n}\left|X_{i}-X_{i+1}\right|$

The accuracy of the process variable to that of the set point is calculated using the equation below. The equation calculates the difference between the process variable and the set point such that $Y_{i}$ and $X_{i}$ denote the reading of the set point and process variable values respectively. If the absolute difference between the process variable and set point fall within upper and lower specified control limits, the value of the process variable holds true for a specific range, $n$.

$\operatorname{Accuracy}(\%)=\frac{n-\left(L C L<\sum_{i=1}^{n}\left|Y_{i}-X_{i}\right|<U C L\right)}{n} \times 100$

\section{Results and Discussion}

\subsection{Load Increase Case}

The response of the system due to a load increase case can be viewed in figures 9-14. The MW load set point has been ramped from $160 \mathrm{MW}$ at 50s into the simulation to a final value of $185 \mathrm{MW}$. The ramp rate of the load controller is specified at $10 \mathrm{MW} / \mathrm{min}$. The unit efficiency is specified at $100 \%$ with a frequency correction of $0 \mathrm{~Hz}$. The load increase will occur at a full load capability. Therefore, all mills and draught groups are operational.

During a load increase case, all controllers prove to be empirically correct as they follow relevant direction and amplitude.

The neural network controller outperforms the conventional PID controllers during a load increase transient state. Especially in the case of controlling steam pressure. Unlike the conventional PID controller, the neural network has the ability to decrease the output of the pressure controller during a load increase. Therefore, the control system is able to maintain a steady control of steam pressure during the transient state, thus allowing for a far smaller dead band of the critical process values than that of PID control.

The figures 9 to 14 illustrate the response of the system due to a load increase case. The response from conventional PID and neural network are denoted as PID and NN respectively.

The performance parameters include the duty cycle of the mechanical actuator associated with the critical parameter, the total percentage movement of the process value and the control output (CO), and the accuracy (as a percentage) of the process value to that of the set point within one percent.

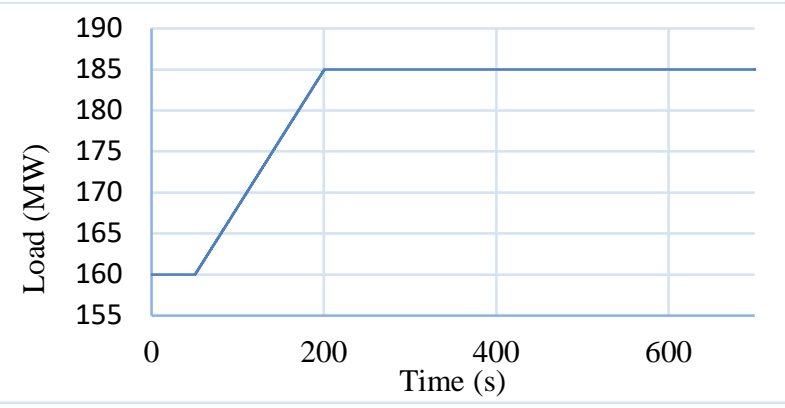

Figure 9 MW Load set point

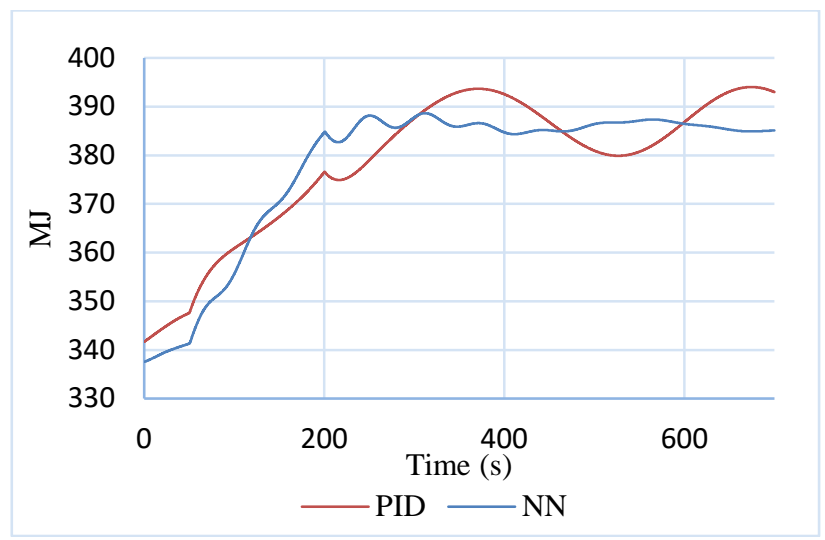

Figure 10 Boiler MJ Load Response

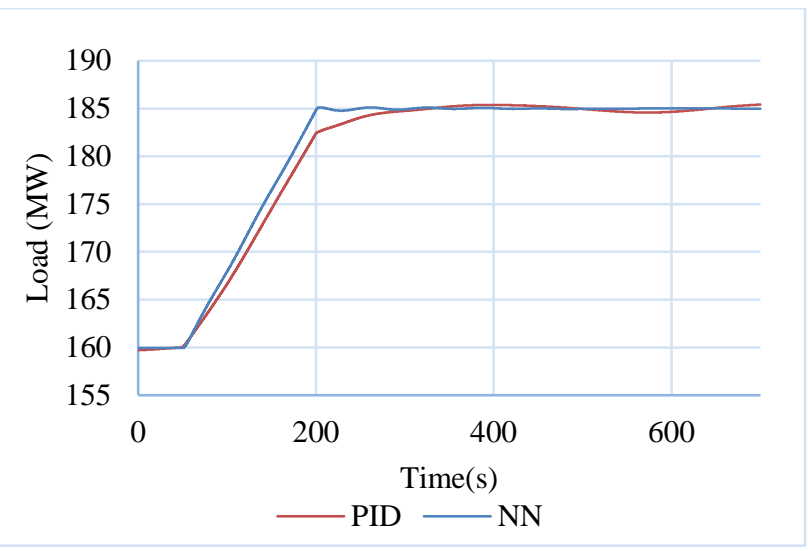

Figure 11 Boiler MW Load Response

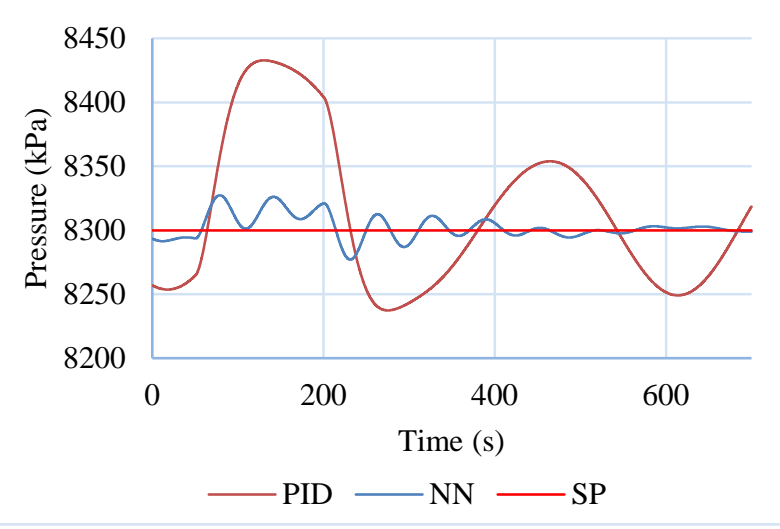

Figure 12 Boiler Steam Pressure Response 


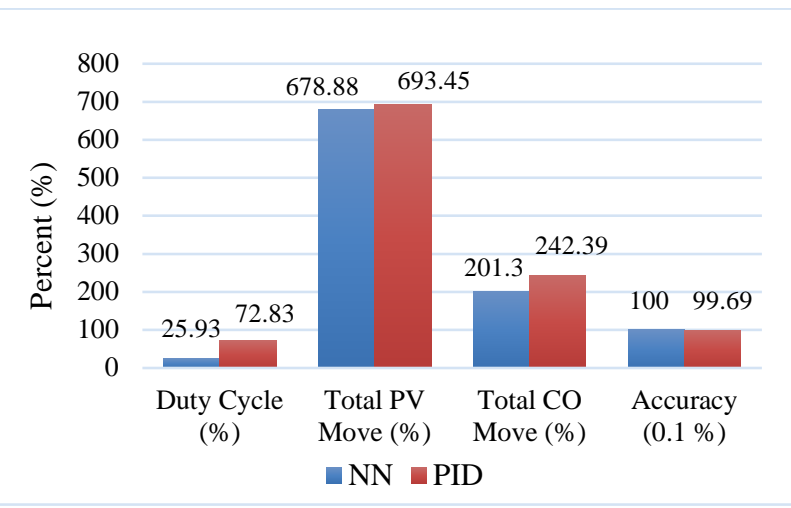

Figure 13 MW Load Condition Monitoring Performance Parameters for Load Increase Case

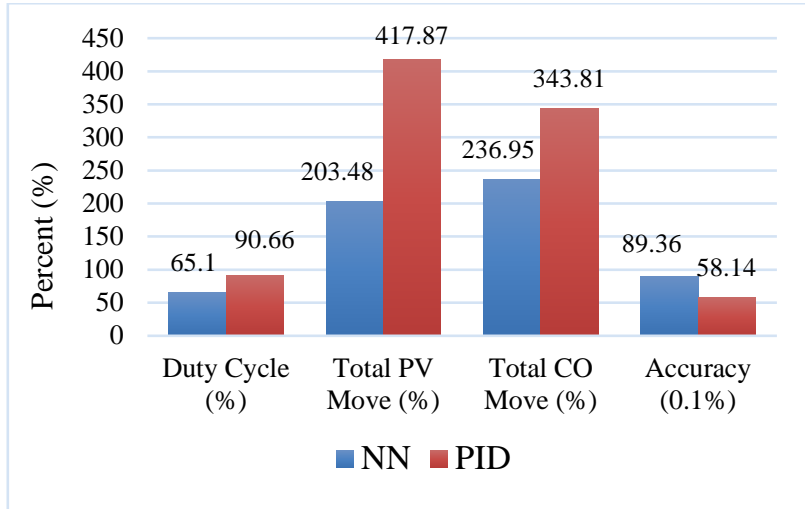

Figure 14 Steam Pressure Condition Monitoring Performance Parameters for Load Increase Case

\subsection{Mill Trip Case}

The response of the system due to a mill trip case can be viewed in the figures below. During a mill trip, the MW load setpoint is set to $200 \mathrm{MW}$. At 50s into the simulation, one of the mills are tripped, dropping the unit capability by $25 \%$. Since the upper load limit is specified as $210 \mathrm{MW}$, the MW load setpoint drops $25 \%$ to a value of $157,5 \mathrm{MW}$. The MW load decreases at a ramp rate of $10 \mathrm{MW} / \mathrm{min}$. At 200s, the mill is brought back into service and the MW load setpoint is restored to $200 \mathrm{MW}$ at a ramp rate of $10 \mathrm{MW} / \mathrm{min}$.

The trends show that as a mill trip occurs, the capability computation of the plant decreases by $25 \%$. Hence, decreasing the boiler load demand by $10 \mathrm{MW} / \mathrm{min}$. A consequence of a decreased load demand causes a decrease in the steam mass flow as the load controller forces the steam valve to close in order to maintain a steady load demand. The decrease in steam mass flow causes the steam quality in the boiler drum decreases, thus causing the water level in the boiler drum to rise. With an increased water level, the drum level controller slowly closes the feed-water valve to accommodate for the change.

The results obtained illustrate that the neural network control system outperforms the conventional PID control in a mill trip case. The intelligent control system possesses an exceptionally fast response time with little overshoot. Thus, allowing for decreased process value fluctuations.
The neural network control system performs very well in the case of steam pressure and MW load control with little overshoot and fast response time. Once a mill trip occurs and the load demand decreases, the PID control system increases the output of the pressure controller therefore causing pressure losses in the plant. However, the neural network controller has the ability to decrease the control output and therefore maintain a steady steam pressure during a mill trip case.

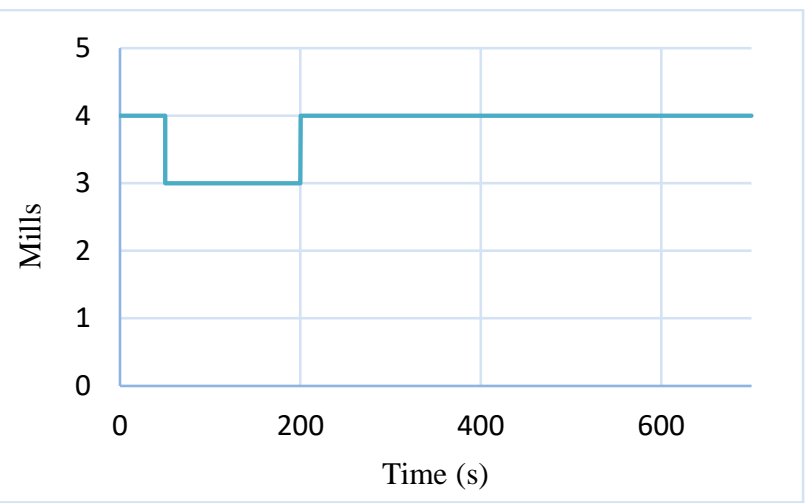

Figure 15 Number of mills online

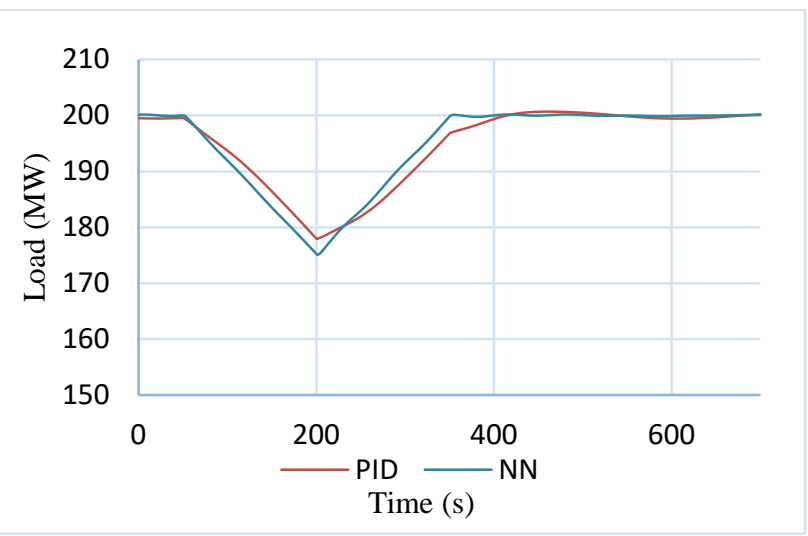

Figure 16 MW Load Response

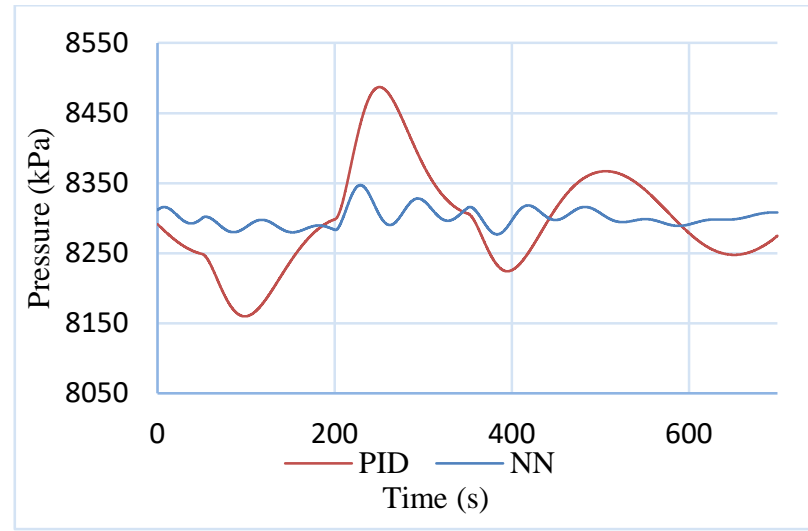

Figure 17 Boiler Steam Pressure Response

$R \& D$ Journal of the South African Institution of Mechanical Engineering 2021, 37, 9-18 


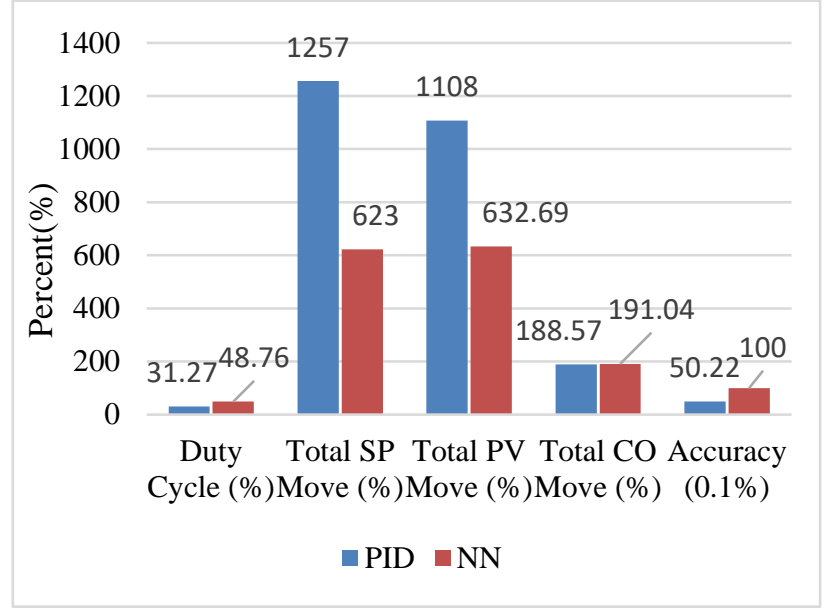

Figure 18 MW Load Condition Monitoring Performance Parameters for Mill Trip Case

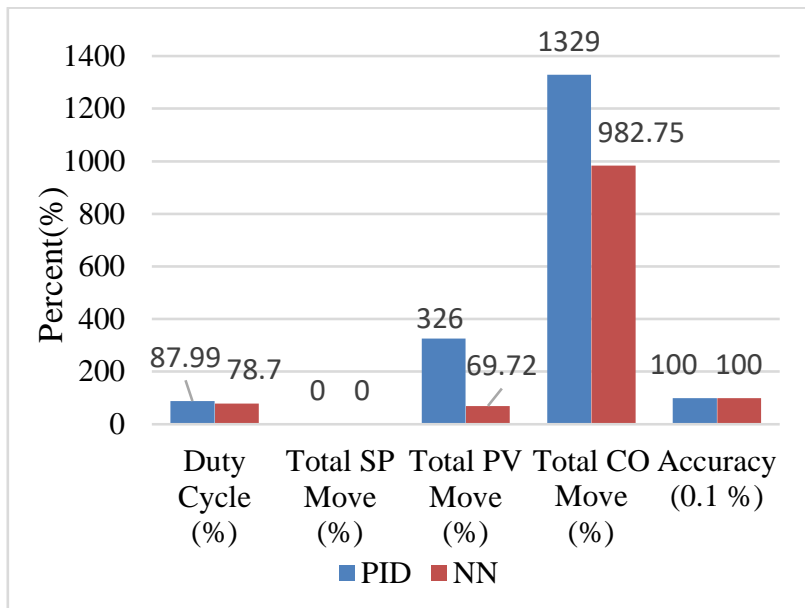

Figure 19 Steam Pressure Condition Monitoring Performance Parameters for Load Increase Case

\section{Conclusion}

In order to evaluate the performance of boiler sub-systems, in this research, a thermo-fluid model was modelled in accordance to the mechanical and process characteristics of an existing power plant. The model consists of a boiler steam drum, evaporator, superheater, attemperator, high pressure and low-pressure turbines. In addition, the thermo-fluid model has been calibrated to that of the Rankine cycle of the existing plant in order to provide optimised and accurate responses to control system behaviour.

The control systems designed to optimise the critical process parameters were developed in order to reduce process value fluctuations, in turn, reducing movement on mechanical actuators such as valves, fan vanes etc. Validated results are thus required in order to understand the behaviour of the control systems as well as determine the correct action required in developing optimised controllers. Therefore, a condition monitoring algorithm was developed in order to measure the performance of the control system based on the process data, this includes the accuracy of the process value to that of the set point, the duty cycle of the control output as well as the total percentage movement of the process value.

Conventional function block proportional-plusderivative-plus-integral control system as well as intelligent controllers such as artificial neural networks were developed to optimise the critical process parameters.

The results for each control system obtained in figures 9 to 14 clearly illustrates that regardless of the extensive use of control measures, the neural network controller outperforms the proportional-plus-integral-plus-derivative controller in terms of the duty cycle of the control output, PV accuracy and the total percentage movement of the control output. Figure 11 illustrates that although the MW load controller obtains little overshoot and a fast response time using PID control, the increased duty cycle and total movement of the control output causes increased wear on mechanical components such as the coal feeders, fan vanes and steam valves. Thus, decreasing the plant life cycle.

In conclusion, the developed model allows to predict behaviour of the boiler and its subsystems. This allows control engineers to observe fluctuations of the critical process parameters, as well, as to perform a sensitivity analysis and to assist control engineers to improve the plant efficiency.

In a load increase case of $160 \mathrm{MW}$ to $185 \mathrm{MW}$ with a runtime of 700 seconds for Boiler Steam Pressure control. The Machine Learning algorithm achieved a total percentage movement on boiler $\mathrm{MJ}$ and boiler steam pressure of $1134.48 \%$ and $75.46 \%$ respectively. In the same case, the PID control regime achieved a total percentage movement on the boiler MJ and boiler steam pressure of $1712.29 \%$ and $132.7 \%$ respectively. Thus, it is evident that the Machine Learning algorithm is able to significantly decrease process variability to that of the conventional PID controllers and in turn reduce the duty cycle of mechanical actuators.

For a mill trip case in which one of four mills tripped for 150 seconds. The Machine Learning controller was able to maintain a stable boiler steam pressure with a total percentage movement for boiler steam pressure of $69.2 \%$ compared to a total movement of $326 \%$ from the PID controller. Although there were slightly greater fluctuations in the control output during the mill trip case in order to maintain the steady process value. This is evident from the $31.2 \%$ duty cycle generated by the PID controller and a $48.7 \%$ duty cycle from the NN.

The Machine Learning controller was able to outperform the PID controller for most aspects in terms of plant stability, process value accuracy including steady and responsive control given various plant disturbances.

\section{Acknowledgments}

The authors would like to acknowledge the Eskom Power Plant Engineering Institute for funding the project and thank Mr Carel Potgieter for his support and guidance. 


\section{References}

[1] S. G. Dukelow. The Control of Boilers. ISA Instrumentation, Systems and Automation Society, $2^{\text {nd }}$ edition, 1991.

[2] J. Feltas. Boiler Effects on Steam Turbine Response. Power Tech, New York, 2004.

[3] G. F. Gilman. Boiler Control Systems Engineering. ISA - Instrumentation, Systems and Automation Society, 2005.

[4] A. E. Ruano. Intelligent Control Systems using Computational Intelligent Techniques. Lightning Source, 2005.

[5] L. Wang. The Application of Fuzzy Neural Network to Boiler Steam. International Journal of Computer Science Issues, 10(1):704-707, 2013.

[6] P. Tanwar and B. S. Tanwar. Boiler Furnace Pressure Excursion and Set Points. International Journal of Computer Applications, 1(12):14-16, 2010.

[7] H. Kristinsson and S. Lang. Boiler Control - Improving Efficiency of Boiler Systems. Master Thesis, Division of Industrial Electrical Engineering and Automation, Lund University, Lund, Sweden, 2010.

[8] F. Morilla. Benchmark for PID Control Based on the Boiler Control Problem. Escuela Técnica Superior de Ingeniería Informática, UNED, Madrid, Spain, 2012.

[9] H. Archay. Condition Monitoring and Performance Optimisation of Vertical Spindle Type Mills. Master thesis, University of the Witwatersrand, Johannesburg, South Africa, 2015.

[10]A. Rossouw. Boiler System Modelling using Flownex. Master thesis, University of Cape Town, Cape Town, South Africa, 2015.

[11]H. Pan. W. Zhong. Z. Wang and G. Wang. Optimization of industrial boiler combustion control system based on genetic algorithm. Computers and Electrical Engineering, 70, 987-997, 2018.

[12]D. Lindsley. Power Plant Control and Instrumentation: The Control of Boilers and HRSG Systems. Lightning Source, 2000.

[13]A. Kellerman. The Development of Boiler Control Models for the Optimization of Boiler Efficiency, Nelson Mandela Metropolitan University, Port Elizabeth, South Africa, 2016.

[14]NMMU. Eskom Report 2016, Nelson Mandela Metropolitan University, Port Elizabeth, South Africa, 2016.

[15]R. Leimbach. Steam Pressure Control using Direct Energy Balance, Power Mag. URL http://www.powermag.com/drum-pressure-the-key-tomanaging-boiler-stored-energy/?pagenum $=4$, 2007

[16]A. P. Engelbrecht. Computational Intelligence-An Introduction. Wiley, Chichester, 2007.

[17]L. Van der Westhuizen and I. A. Gorlach. Modelling of boiler drum level control using Flownex software environment. WSEAS Transactions on Systems, 2019, 129-137.

R \& D Journal of the South African Institution of Mechanical Engineering 2021, 37, 9-18 